\title{
Clinical association of vitamin D and serotonin levels among patients with fibromyalgia syndrome
}

This article was published in the following Dove Press journal:

Neuropsychiatric Disease and Treatment

\author{
Omar A Amin' \\ Saleh M Abouzeid ${ }^{2}$ \\ Siham A Ali ${ }^{3}$ \\ Bashir A Amin ${ }^{4}$ \\ Khaled A Alswat ${ }^{5}$ \\ 'Department of Orthopedic, Al Noor \\ Specialist Hospital, Makkah, Saudi Arabia; \\ ${ }^{2}$ Department of Rheumatology, Al Azhar \\ University, Cairo, Egypt; ${ }^{3}$ Department of \\ Neurology, Banha University, Banha, Egypt; \\ ${ }^{4}$ Department of Medicine, Taif University, \\ School of Medicine, Taif, Saudi Arabia; \\ ${ }^{5}$ Department of Medicine and \\ Endocrinology, Taif University School of \\ Medicine, Taif, Saudi Arabia
}

\begin{abstract}
Objective: Fibromyalgia syndrome (FMS) is a chronic disorder associated with severe pain. According to the National Fibromyalgia Association, the prevalence of FMS is between 3\% and $6 \%$ in the general population, with about $90 \%$ of the patients being women. The primary goal of this study was to evaluate the relationship between vitamin D and serotonin levels and FMS severity.

Methods: Forty participants with fibromyalgia (mean age: $37.8 \pm 9.5$ years) were included and had their medical history taken, a physical examination, and laboratory testing in the Rheumatology Department at Al-Ameen Hospital in Taif, Saudi Arabia. The revised Fibromyalgia Impact Questionnaire (FIQR) was used to determine the FMS severity.

Results: The results showed that $42.5 \%$ of the patients were considered to have mild/ moderate fibromyalgia, with the remainder having severe/extreme fibromyalgia. The latter were more likely to have lower serotonin levels. The results showed a significant dosedependent negative relationship between the serotonin levels and FIQR scores $(P=0.002)$. However, no significant correlations were found between the vitamin D levels and FIQR scores $(P=0.112)$.
\end{abstract}

Conclusion: The findings of this study show that the improved health of FMS patients is associated with normal serotonin levels.

Keywords: fibromyalgia, vitamin D, serotonin, Saudi Arabia, Taif

\section{Introduction}

Fibromyalgia is the second most common disorder for which patients are usually directed to rheumatology clinics. ${ }^{1-3}$ Fibromyalgia syndrome (FMS) is a chronic disorder associated with a severe pain that can affect a patient's musculoskeletal system, daily routine, and mood. ${ }^{3,4}$ According to the National Fibromyalgia Association, the prevalence of FMS has been reported as 3\% to $6 \%$ of the general population, and $\sim 90 \%$ of the patients are women. ${ }^{5}$ The symptoms of fibromyalgia usually appear between the ages of 20 and 50 years old. However, the incidence rises with age, with more than $7 \%$ of the patients in the 70 - to 80 -year age range meeting the criteria as set forth by the American College of Rheumatology Classification of Fibromyalgia.

Serotonin, also known as 5-hydroxytryptamine (5-HT), is one of the most important monoamine neurotransmitters in humans. It is generated by the central nervous system, particularly in serotonergic neurons. ${ }^{6,7}$ Serotonin influences the brain in matters such as behavioral control, cognitive performance, emotional aspect, and mood swings. ${ }^{8,9}$ Hence, a decrease in serotonin levels may be associated with several disorders such as major depression, aggressive behavior, bipolar
Correspondence: Omar A Amin Al Noor Specialist Hospital, 3rd Ring Rd, An Naseem, Makkah, 24242, Saudi Arabia Tel +96 6552245586

Email omar.amin1415@gmail.com 
disorder, and sudden infant death syndrome. ${ }^{10}$ Many researchers have indicated that FMS is also associated with low serotonin levels. ${ }^{11,12}$

Vitamin D is an important element for human nutrition. It is an essential vitamin that is classified as a steroid hormone, and it affects calcium and phosphate levels in the blood. ${ }^{13}$ In addition, vitamin D $(25-\mathrm{OH})$ is considered the active form of vitamin $\mathrm{D},{ }^{14}$ and a deficiency can lead to many musculoskeletal diseases such as osteomalacia, rickets, and osteoporosis. ${ }^{15,16}$ The exact pathophysiology of FMS is still unclear, although several studies have also linked vitamin D deficiency to FMS. ${ }^{17,18}$ However, studies examining the relationship of vitamin $\mathrm{D}$ and serotonin levels in fibromyalgia patients are lacking.

Our primary goal was to evaluate the prevalence of vitamin D deficiency and low serotonin levels among randomly selected FMS patients. We also assessed the relationships between vitamin D and serotonin levels and FMS severity.

\section{Materials and methods}

A cross-sectional study was designed and conducted at the Rheumatology Department of Al-Ameen Hospital in Taif, Saudi Arabia between September 2017 and April 2018. Forty patients (32 females, 8 males; aged 20-60 years) diagnosed with FMS according to the American College of Rheumatology FMS classification criteria were selected from the rheumatology clinic at Al-Ameen Hospital. We excluded all patients with musculoskeletal problems, those with rheumatoid arthritis or systemic lupus erythematosus, and those with a psychiatric diagnosis.

This study was approved by the Research Ethics Committee of Taif University, Saudi Arabia (No.: 39-360141). Regarding the patient privacy and medical ethics, all patients were informed that their data will be used for the research purposes. In accordance with the declaration of Helsinki, all patients provided an oral consent, which was approved by Taif University IRB.

All patients had their medical history taken and were clinically assessed according to the American College of Rheumatology criteria. These criteria aim to do the following: (1) assess the pain and symptoms over the past week for 19 body parts (FMS tender points) and measure the severity level of the symptoms fatigue, waking unrefreshed, and cognitive (memory or thought) problems; (2) determine if the symptoms have lasted continuously over at least three months at a similar level; and (3) ensure that no other health problems exist that would explain the pain and other symptoms.
Blood samples were obtained from the FMS patients to determine the vitamin $\mathrm{D}(25-\mathrm{OH})$ and serum serotonin levels, and a questionnaire was distributed. The questionnaire consisted of two parts: a demographic questionnaire and the revised Fibromyalgia Impact Questionnaire (FIQR). ${ }^{19}$ The demographic questionnaire included the age, sex, educational status, income level, body mass index (BMI), daily caffeinated beverage consumption, smoking status, and medication usage. The FIQR questionnaire was used to determine the FMS severity based on the total FIQR score. The FIQR questionnaire contains 21 separate questions divided into three parts: (a) 9 functional questions, (b) 2 overall impact questions, and (c) 10 symptom questions. ${ }^{19}$ The patients were divided into groups based on four different FIQR score ranges: 0-42, mild; 43-59, moderate; 60-74, severe; and 75-100, extreme. ${ }^{19}$

After the blood samples were collected from the patients, the vitamin D status was determined and the 25 $(\mathrm{OH}) \mathrm{D}$ values were classified as deficient $(\leq 20 \mathrm{ng} / \mathrm{mL})$ or normal $(>20 \mathrm{ng} / \mathrm{mL}) .{ }^{20}$ The serum serotonin levels were determined by an enzyme-linked immunosorbent assay and classified as low $(<68 \mathrm{ng} / \mathrm{mL})$ or normal $(\geq 68 \mathrm{ng} / \mathrm{mL})$, with the normal range being $68-232 \mathrm{ng} / \mathrm{mL}$.

The data were analyzed using the Statistical Package for the Social Sciences (SPSS) (IBM Corp., Armonk, NY, USA) version 20.0. Frequencies and percentages were used to evaluate each variable. Chi-square tests were used to study the relationships between variables, and sample $t$-tests were used to compare means.

\section{Results}

Forty participants with fibromyalgia (mean age: $37.8 \pm 9.5$ years) were recruited (Table 1). The majority were female and married, and almost half had a low educational level. The mean BMI was $29.5 \pm 5.0$, with $40 \%$ in the overweight category. About $22.5 \%$ of the patients had hypertension. In terms of medication use, most of the patients were using a painkiller. The data also showed that more than twothirds of the patients were smokers, and one-third were active smokers. Seventy percent of the patients consumed more than 4 cups of caffeinated beverages per day.

The average FIQR score was $62.2 \pm 17.2$, and more than half the patients $(57.5 \%)$ were categorized as having severe or extreme fibromyalgia. The laboratory tests showed the mean serotonin level was $87.1 \pm 76.3(\mathrm{ng} / \mathrm{mL})$, and the mean vitamin D level was $23.1 \pm 9.8(\mathrm{ng} / \mathrm{mL})$. More than half the patients $(60 \%)$ had low vitamin $\mathrm{D}$ and serotonin levels. 
Table I Baseline characteristics of the whole cohort

\begin{tabular}{|c|c|}
\hline \multicolumn{2}{|l|}{ Baseline characteristics $(\mathrm{N}=40)$} \\
\hline Mean age (yrs) & $37.8 \pm 9.5$ \\
\hline Male (\%) & 20 \\
\hline High school education or less (\%) & 45 \\
\hline Low income (\%) & 20 \\
\hline Single (\%) & 40 \\
\hline Divorced (\%) & 7.5 \\
\hline Hypertension (\%) & 22.5 \\
\hline \multicolumn{2}{|l|}{ Medications/supplements } \\
\hline Painkillers (\%) & 65 \\
\hline Painkillers and multivitamin (\%) & 15 \\
\hline \multicolumn{2}{|l|}{ BMI categories } \\
\hline Mean BMI $\left(\mathrm{kg} / \mathrm{m}^{2}\right)$ & $29.5 \pm 5.0$ \\
\hline Normal weight (\%) & 12.5 \\
\hline Overweight (\%) & 40 \\
\hline Obese (\%) & 47.5 \\
\hline \multicolumn{2}{|l|}{ Fibromyalgia Impact Questionnaire (FIQR) data } \\
\hline Mean FIQR score & $62.2 \pm 17.2$ \\
\hline Mild FIQR (\%) & 17.5 \\
\hline Moderate FIQR (\%) & 25 \\
\hline Sever FIQR (\%) & 25 \\
\hline Extreme FIQR (\%) & 32.5 \\
\hline Pain affects/limit the daily routine activity (\%) & 75 \\
\hline \multicolumn{2}{|l|}{ Laboratory data } \\
\hline Mean serotonin level (ng/ml) & $87.1 \pm 76.3$ \\
\hline Normal serotonin level (\%) & 40 \\
\hline Low serotonin level (\%) & 57.5 \\
\hline Mean vitamin D level (ng/ml) & $23.1 \pm 9.8$ \\
\hline Normal vitamin D level (\%) & 40 \\
\hline Deficient vitamin D level (\%) & 60 \\
\hline \multicolumn{2}{|l|}{ Caffeine and energy drinks } \\
\hline None (\%) & 2.5 \\
\hline$\leq 4$ cups per day $(\%)$ & 27.5 \\
\hline$>4$ cups per day $(\%)$ & 70 \\
\hline \multicolumn{2}{|l|}{ Lifestyle habits } \\
\hline Active smoking (\%) & 30 \\
\hline Passive smoking (\%) & 77.5 \\
\hline
\end{tabular}

A quarter of the patients (25\%) had moderate fibromyalgia, while $17.5 \%$ had mild fibromyalgia (Table 2 ). As high as $25 \%$ of the patients with severe fibromyalgia and $32.5 \%$ with extreme fibromyalgia were more likely to have lower serotonin levels $(P=0.002)$ and less likely to have normal vitamin $\mathrm{D}$ levels $(P=0.029)$. However, those with severe/extreme fibromyalgia were more likely to be male $(P=0.749)$, report a low income $(P=0.665)$, be married $(P=0.727)$, and have hypertension $(P=0.527)$. They were less likely to
Table 2 Correlation analyses between different variables and FIQR scores

\begin{tabular}{|c|c|c|c|}
\hline & $\begin{array}{l}\text { Mild } / \\
\text { moderate }\end{array}$ & $\begin{array}{l}\text { Severel } \\
\text { extreme }\end{array}$ & $\begin{array}{l}P \text {-val- } \\
\text { ue }\end{array}$ \\
\hline Number of patients (\%) & 42.5 & 57.5 & $\mathrm{n} / \mathrm{a}$ \\
\hline Mean age (yrs) & $36.7 \pm 9.7$ & $38.7 \pm 9.5$ & 0.509 \\
\hline Male (\%) & 17.7 & 21.7 & 0.749 \\
\hline $\begin{array}{l}\text { High school education or } \\
\text { less (\%) }\end{array}$ & 47.1 & 43.5 & 0.461 \\
\hline Low income (\%) & 17.6 & 21.7 & 0.665 \\
\hline Single (\%) & 47.1 & 34.8 & 0.727 \\
\hline Divorced (\%) & 5.9 & 8.7 & \\
\hline Hypertension (\%) & 17.6 & 26.1 & 0.527 \\
\hline \multirow{3}{*}{$\begin{array}{l}\text { Medications/ } \\
\text { supplements } \\
\text { Painkillers (\%) } \\
\text { Painkillers and multivitamin } \\
\text { (\%) }\end{array}$} & & & \\
\hline & 82.4 & 52.2 & 0.260 \\
\hline & 5.9 & 21.7 & \\
\hline \multicolumn{4}{|l|}{ BMI categories } \\
\hline Mean BMI $\left(\mathrm{kg} / \mathrm{m}^{2}\right)$ & $30.2 \pm 5.3$ & $28.9 \pm 4.9$ & 0.418 \\
\hline Normal weight (\%) & 5.9 & 17.4 & 0.541 \\
\hline Overweight (\%) & 41.2 & 39.1 & \\
\hline Obese (\%) & 52.9 & 43.5 & \\
\hline \multicolumn{4}{|l|}{$\begin{array}{l}\text { Fibromyalgia Impact } \\
\text { Questionnaire (FIQR) } \\
\text { data }\end{array}$} \\
\hline Mean FIQR score & $45.5 \pm 9.9$ & $74.4 \pm 9.2$ & $<0.001$ \\
\hline $\begin{array}{l}\text { Pain affects/limit the daily } \\
\text { routine activity (\%) }\end{array}$ & 76.5 & 73.9 & 0.853 \\
\hline \multicolumn{4}{|l|}{ Laboratory data } \\
\hline Mean serotonin level $(\mathrm{ng} / \mathrm{mL})$ & $127.9 \pm 78.2$ & $57.0 \pm 60.3$ & 0.002 \\
\hline Normal serotonin level (\%) & 64.7 & 21.7 & 0.007 \\
\hline Mean vitamin D level ( $\mathrm{ng} / \mathrm{mL})$ & $25.9 \pm 12.4$ & $20.9 \pm 7.0$ & 0.112 \\
\hline Normal vitamin D level (\%) & 47.1 & 34.8 & 0.029 \\
\hline \multicolumn{4}{|l|}{$\begin{array}{l}\text { Caffeine and energy } \\
\text { drinks }\end{array}$} \\
\hline None (\%) & 0 & 4.3 & 0.677 \\
\hline$\leq 4$ cups per day (\%) & 29.4 & 26.1 & \\
\hline$>4$ cups per day (\%) & 70.6 & 69.6 & \\
\hline \multicolumn{4}{|l|}{ Lifestyle habits } \\
\hline Active smoking (\%) & 29.4 & 30.4 & 0.944 \\
\hline Passive smoking (\%) & 76.5 & 78.3 & 0.893 \\
\hline
\end{tabular}

use painkillers $(P=0.260)$ and had a lower mean BMI $(P=0.418)$ and lower vitamin $\mathrm{D}$ levels $(P=0.112)$.

The results showed a significant dose-dependent negative relationship between the serotonin levels and FIQR scores ( $P=0.002$; Figure 1), but no significant correlation was seen between the vitamin D levels and FIQR scores $(P=0.112$; Figure 2). A partial correlation adjusted for age, marital status, 


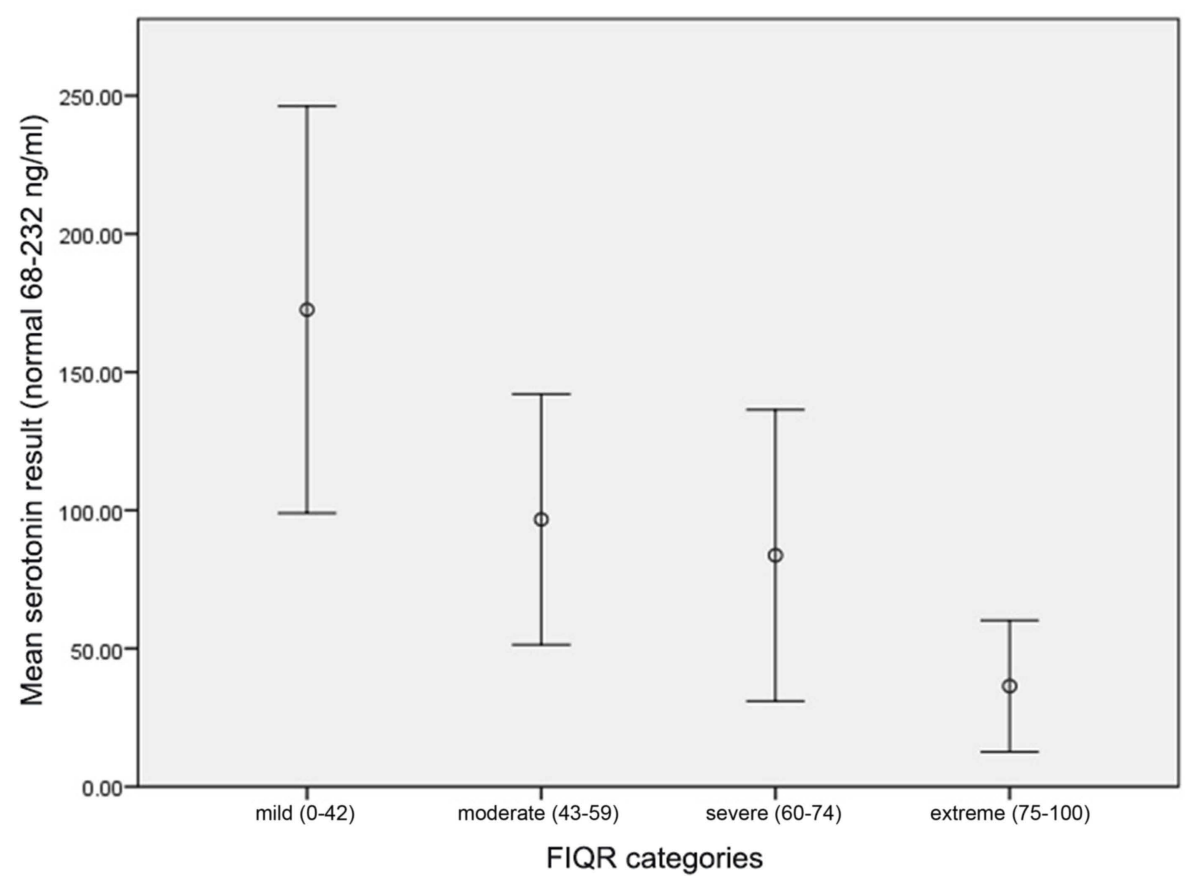

Figure I Serotonin level according to the FIQR categories, it shows a significant negative correlation between serotonin level and FIQR scores.

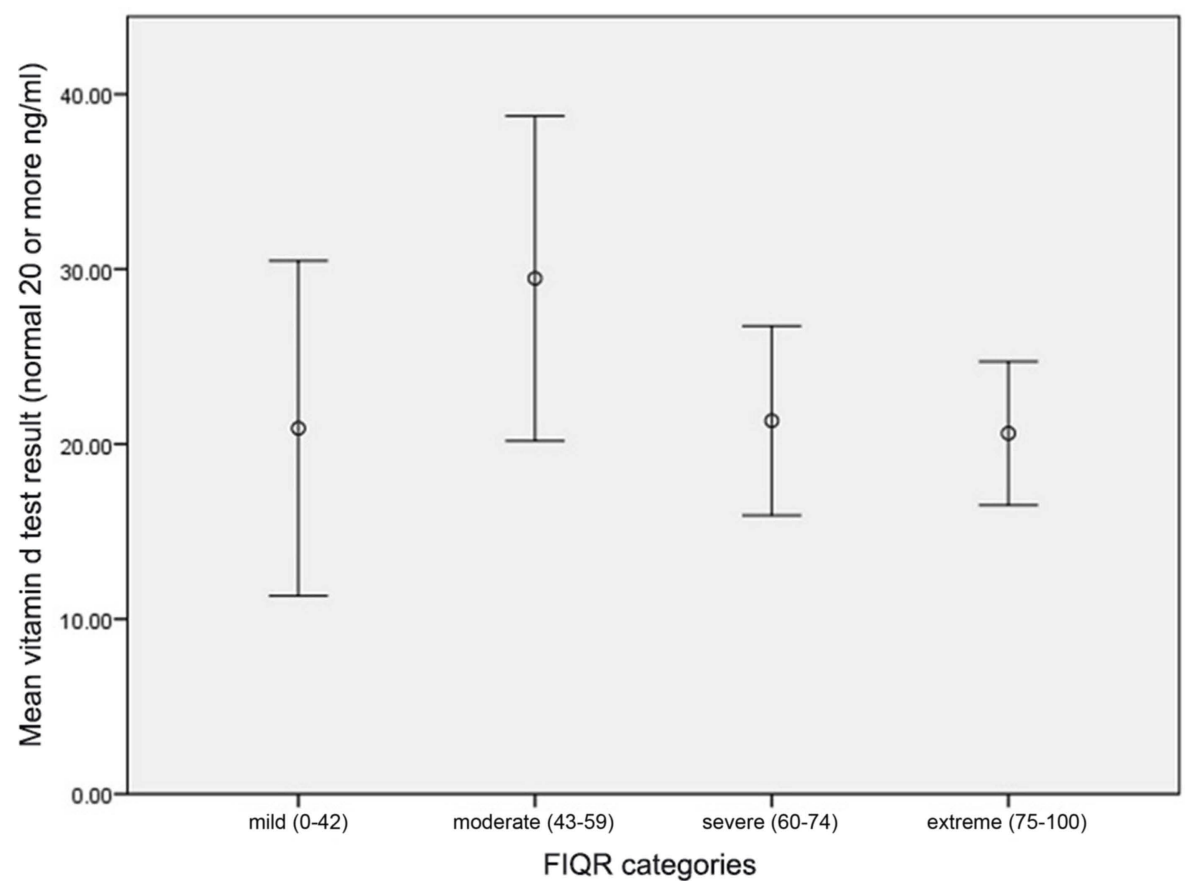

Figure 2 Vitamin D level according to the FIQR categories, it shows there is no significant positive correlation between vitamin D level and FIQR scores.

education, income, BMI, caffeine intake, smoking, and hypertension also showed a significant negative correlation between the serotonin levels and the FIQR scores $(\mathrm{r}=-0.520, P=0.002)$ and a non-significant positive correlation between the vitamin $\mathrm{D}$ levels and FIQR scores $(\mathrm{r}=0.015, P=0.935)$.

\section{Discussion}

This study investigated the relationship between vitamin $\mathrm{D}$ and serotonin levels among patients with FMS. Our results indicated there is an association between FMS and hypertension, with $22.5 \%$ of the FMS patients having 
high blood pressure. This finding corresponds with a study by the de Rezende Pena group, ${ }^{13}$ which found $26.4 \%$ of the FMS patients have such an association, as well as other medical studies indicating similar results. ${ }^{21,22}$ The findings also showed a clear association exists between obesity and FMS among the patients. This outcome is consistent with other medical studies. ${ }^{13,23}$ These phenomena of increased BMI and hypertension in association with other medical comorbidities and a lack of exercise can be due to psychological issues such as depression. ${ }^{23}$

In addition, a negative relationship between the serotonin levels and FIQR scores $(P=0.002)$ was indicated in this study (Figure 1), which is consistent with previous research. A study by the El Shazly group ${ }^{24}$ observed a significant decrease in serotonin levels $(P=0.001)$ among FMS patients. In another study, serotonin levels were decreased by more than $44 \%$ in FMS patients in comparison with healthy individuals. ${ }^{25}$ However, low serotonin levels are not necessarily linked with the occurrence of FMS, as other factors such as pathological serotonin receptors or anti-5 HT receptor antibodies are also associated with low serotonin levels. ${ }^{26}$ Several medications are available that can help treat FMS, and selective serotonin reuptake inhibitors are considered an effective treatment. $^{27}$

In terms of the relationship between the vitamin D levels and FIQR scores, there were no significant differences between the variables $(P=0.112)$, which is consistent with the results of a study by the de Rezende Pena group. ${ }^{13}$ However, other medical studies have indicated a vitamin D deficiency is associated with FMS for dietary reasons ${ }^{28,29}$ due to minimal sunlight exposure and a lack of vitamin $\mathrm{D}$ intake by patients.

\section{Conclusions}

The purpose of this study was to investigate the relationships between vitamin $\mathrm{D}$ and serotonin levels among patients with FMS. Forty patients, aged 20-60 years and diagnosed with FMS, were selected from a hospital rheumatology clinic. Our results showed a significant negative correlation between the serotonin levels and FIQR scores and a non-significant positive correlation between the vitamin D levels and FIQR scores. These results support the importance of serotonin medication to improve the symptoms of FMS patients. Given that serotonin levels play a significant role in the FMS diagnosis, doctors should request testing for the serum serotonin level in any patient suspected of having FMS. Finally, increasing the sample size and conducting this study in different regions of Saudi Arabia would be recommended for future studies to enhance our understanding of how serotonin and vitamin D levels influence FMS.

\section{Acknowledgments}

Research assistance support was provided by Hassan M. Awad and Mss. Monnette Farmento.

\section{Disclosure}

The authors report no conflicts of interest in this work.

\section{References}

1. White KP, Speechley M, Harth M, Ostbye T. Fibromyalgia in rheumatology practice: a survey of Canadian rheumatologists. $J$ Rheumatol. 1995;22(4):722-726.

2. Zih FS, Da Costa D, Fitzcharles MA. Is there benefit in referring patients with fibromyalgia to a specialist clinic? J Rheumatol. 2004;31(12):2468-2471.

3. Jones GT, Atzeni F, Beasley M, Flüß E, Sarzi-Puttini P, Macfarlane GJ. The prevalence of fibromyalgia in the general population: a comparison of the American College of Rheumatology 1990, 2010, and modified 2010 classification criteria. Arthritis Rheumatol. 2015;67(2):568-575. doi:10.1002/art.38905

4. Martínez-Lavín M, Hermosillo AG. Autonomic nervous system dysfunction may explain the multisystem features of fibromyalgia. Seminars in arthritis and rheumatism; 2000; WB Saunders. doi:10.1016/S0049-0172(00)80008-6

5. Fibromyalgia prevalenc; 2018. Available from: http://www.fmaware. org/about-fibromyalgia/prevalence. Accessed September 13, 2018.

6. Mazák K, Dóczy V, Kökösi J, Noszál B. Proton speciation and microspeciation of serotonin and 5-hydroxytryptophan. Chem Biodivers. 2009;6(4):578-590. doi:10.1002/cbdv.200800087

7. Atasever M, Namlı Kalem M, Sönmez Ç, et al. Lower serotonin level and higher rate of fibromyalgia syndrome with advancing pregnancy. J Maternal-Fetal Neonatal Med. 2017;30(18):2204-2211. doi:10.1080/14767058.2016.1243096

8. Bauer M, Heinz A, Whybrow P. Thyroid hormones, serotonin and mood: of synergy and significance in the adult brain. Mol Psychiatry. 2002;7(2):140. doi:10.1038/sj.mp.4000963

9. Cools R, Roberts AC, Robbins TW. Serotoninergic regulation of emotional and behavioural control processes. Trends Cogn Sci (Regul Ed). 2008;12(1):31-40. doi:10.1016/j.tics.2007.10.011

10. Paterson DS, Trachtenberg FL, Thompson EG, et al. Multiple serotonergic brainstem abnormalities in sudden infant death syndrome. Jama. 2006;296(17):2124-2132. doi:10.1001/jama.296.17.2124

11. Walitt B, Urrútia G, Nishishinya MB, Cantrell SE, Häuser W. Selective serotonin reuptake inhibitors for fibromyalgia syndrome. Sao Paulo Med J. 2015;133(5):454. doi:10.1590/1516-3180.20151335T1

12. Zhu C, Yu B, Zhang W, Chen W, Qi Q, Miao Y. Effectiveness and safety of transcranial direct current stimulation in fibromyalgia: a systematic review and meta-analysis. J Rehabil Med. 2017;49 (1):2-9. doi:10.2340/16501977-2179

13. de Rezende Pena C, Grillo LP, das Chagas Medeiros MM. Evaluation of 25-hydroxyvitamin D serum levels in patients with fibromyalgia. J Clin Rheumatol. 2010;16(8):365-369. doi:10.1097/ RHU.0b013e3181fe8a90

14. DeLuca HF, Holick MF, Schnoes HK, Suda T, Cousins RJ. Isolation and identification of 1,25-dihydroxycholecalciferol. A metabolite of vitamin D active in intestine. Biochemistry. 1971;10(14):2799-2804. 
15. Levis S, Gomez A, Jimenez C, et al. Vitamin D deficiency and seasonal variation in an adult South Florida population. J Clin Endocrinol Metab. 2005;90(3):1557-1562. doi:10.1210/jc.2004-0746

16. Armstrong D, Meenagh G, Bickle I, Lee A, Curran E, Finch M. Vitamin D deficiency is associated with anxiety and depression in fibromyalgia. Clin Rheumatol. 2007;26(4):551-554. doi:10.1007/ s10067-006-0348-5

17. Badsha H, Daher M, Kong KO. Myalgias or non-specific muscle pain in Arab or Indo-Pakistani patients may indicate vitamin D deficiency. Clin Rheumatol. 2009;28(8):971-973. doi:10.1007/s10067-009-1146-7

18. Kasapoğlu Aksoy M, Altan L, Ökmen Metin B. The relationship between balance and vitamin $25(\mathrm{OH}) \mathrm{D}$ in fibromyalgia patients. Modern Rheumatol. 2017;27(5):868-874. doi:10.1080/14397595.2016.1259603

19. Bennett RM, Friend R, Jones KD, Ward R, Han BK, Ross RL. The revised fibromyalgia impact questionnaire (FIQR): validation and psychometric properties. Arthritis Res Ther. 2009;11(4):R120. doi: $10.1186 / \operatorname{ar} 2783$

20. The trials of vitamin D; 2018. Available at: https://www.aacc.org/pub lications/cln/articles/2013/july/vitamin-d. Accessed September, 2018.

21. Duschek S, Schwarzkopf W, Schandry R. Increased pain sensitivity in low blood pressure. $J$ Psychophysiol. 2008;22(1):20-27. doi:10.1027/0269-8803.22.1.20

22. Wentz K, Archer T. Exercise induced autonomic disengagement and pain in women presenting FM and healthy women: analgesia and blood pressure. Clin Exp Psychol. 2017;3(3):168. Clin Exp Psychol, an open access journ(TRUNCATED). doi:10.4172/2471-2701.1000168
23. Gota CE, Kaouk S, Wilke WS. Fibromyalgia and obesity: the association between body mass index and disability, depression, history of abuse, medications, and comorbidities. J Clin Rheumatol. 2015;21 (6):289-295. doi:10.1097/RHU.0000000000000278

24. El Shazly NZ, Sheir SF, Moustfa SM, Debala SH. Fibromyalgia: clinical evaluation, electrophysiological assessment and serum serotonin level measurement. Egypt J Neurol Psychiatry Neurosurg. 2015;52:2.

25. Cordero MD, Alcocer-Gomez E, Cano-Garcia FJ, de Miguel M, Sanchez-Alcazar JA, Moreno Fernandez AM. Low levels of serotonin in serum correlates with severity of fibromyalgia. Med Clin (Barc). 2010;135(14):644-646. doi:10.1016/j.medcli.2010.05.009

26. Bonaventure P, Kelly L, Aluisio L, et al. Selective blockade of 5-hydroxytryptamine (5-HT)7 receptors enhances 5-HT transmission, antidepressant-like behavior, and rapid eye movement sleep suppression induced by citalopram in rodents. $J$ Pharmacol Exp Ther. 2007;321(2):690-698. doi:10.1124/jpet.107.119404

27. Guymer EK, Littlejohn GO. Pharmacological treatment options for fibromyalgia. Stroke. 2018;13:57.

28. Matthana MH. The relation between vitamin D deficiency and fibromyalgia syndrome in women. Saudi Med J. 2011;32(9):925-929.

29. Karras S, Rapti E, Matsoukas S, Kotsa K. Vitamin D in fibromyalgia: a causative or confounding biological interplay? Nutrients. 2016;8 (6):343. doi: $10.3390 /$ nu8060343

\section{Publish your work in this journal}

Neuropsychiatric Disease and Treatment is an international, peerreviewed journal of clinical therapeutics and pharmacology focusing on concise rapid reporting of clinical or pre-clinical studies on a range of neuropsychiatric and neurological disorders. This journal is indexed on PubMed Central, the 'PsycINFO' database and CAS, and is the official journal of The International Neuropsychiatric Association (INA). The manuscript management system is completely online and includes a very quick and fair peer-review system, which is all easy to use. Visit http://www.dovepress.com/testimonials.php to read real quotes from published authors. 